\title{
Evaluation of In vitro Antidandruff Activity of Biotransformed Material (extract) of Nicotiana tabacum Leaves
}

\author{
Prakash Itankar* and Ashlesh V. Murkute \\ University Department of Pharmaceuticals Sciences, R. T. M. Nagpur University, \\ Nagpur, Mahatma Jyotiba Phule Shaikshnik Parisar, Amaravati road, Nagpur-440033, Maharashtra, India; \\ prakashitankar@hotmail.com* ,dr.avm@rediffmail.com
}

\begin{abstract}
The methods of preparing new derivatives of known substrates were applied to modify organic compounds like Carbohydrates, steroids, sterols, terpenoids, flavonoids, alkaloids, antibiotics, amino acids etc. Such alteration encompasses many changes in the substrate moiety by the addition, degradation or modification. When basic structure of resultant molecule remains unaltered, the microbial biotransformation can be applied for formation of desired derivatives of precursor. Aim: To determine the in-vitro anti-dandruff activity of biotransformed material of Nicotiana tabacum leaves. Material and Method: The collected leaves about $200 \mathrm{~g}$ were macerated in cow urine (1 L) for time period of 28 days. After the completion of this time period, the biotransformed material was harvested, lyophilized and powdered $(20 \mathrm{~g})$. Regular aqueous extract of the leaves was also prepared for comparative study. Various concentrations, such as $12.5,25,50,100,500 \mathrm{mg} / \mathrm{ml}$, of aq. extract and biotransformed material of Nicotiana tabacum leaves were prepared and tested for in vitro anti dandruff activity using strain of Malassezia (Pityrosporum) furfur and compared with marketed ayurvedic, homoepathic and allopathic (Ketoconazole 2 \%) formulations. Result: The regular extract and the biotransformed material were screened for phytochemicals. It showed the presence of alkaloids, prominently. The strains responsible for the biotransformation process were also evaluated and identified as Bacillus licheniformis and Bacillus megaterium. The biotransformed material of Nicotiana tabacum leaves shows promising effect against Malassezia (Pityrosporum) furfur, in terms of zone of inhibition of about $7 \mathrm{~mm}$ at 100 $\mathrm{mg} / \mathrm{ml} 26 \mathrm{~mm}$ at $500 \mathrm{mg} / \mathrm{ml}$, respectively. The results were found promising as compared to the regular aqueous extract, marketed formulations including Ketoconazole $2 \%$ preparation. Conclusion: The study shows the improved potential of the cow urine biotransformed material over the normal extract of the same plant. It was evident that the dandruff growth was significantly inhibited by treatment with biotransformed material. Hence, in vitro studies of microbial biotransformed Nicotiana tabacum leaves was found to have a potential anti-dandruff activity between $100 \mathrm{mg} / \mathrm{ml}$ to $500 \mathrm{mg} / \mathrm{ml}$, compared with its aqueous extract, marketed ayurvedic, homoepathic and allopathic formulations.
\end{abstract}

Keywords: Biotransformation, Malassezia furfur, Nicotiana tabacum

\author{
${ }^{*}$ Author for correspondence \\ Email: prakashitankar@hotmail.com
}




\section{Introduction}

A proper health care system can be established, supplying low cost medicine to population by using various medicinal plants. Medicinal plants are usually used for Ayurvedic, Unani and other treatments in rural areas. Recent discovery shows that these plants have fewer side effects than the Allopathic medicine. The medicinal importance of these plants is due to the presence of secondary metabolites present in them. Some of the important bioactive compounds are alkaloids, glycosides, triterpenoids, terpenoids, flavonoids, polyphenols, reducing sugars, saponins, steroids and tannins etc. The traditional medicine is used in all

parts of the world and it's economic importance is also rapidly growing ${ }^{1,18}$. (Dash et al., 2005; Agra et al., 2007; Ushimaru et al., 2007). Globally researchers are using extracts of plants for their antibacterial, antifungal and antiviral activities (Bakht et al., 2011 a, b, c and d). Among the plants, Nicotiana tabacum leaves been used in ayurvedic medicine and has a wide number of traditional uses. Yildirim et al. ${ }^{22}$ reported that the ether extracts of both the leaves and seeds and ethanol

extract of leaves had shown antimicrobial activities. Tobacco, nicotine inhibits the growth of pathogens which is dose dependent ${ }^{14,21}$ (Suresh et al., 2008). It is equally affective against gram- positive and gram-negative bacteria. Thus by considering all above properties of nicotine, plant $N$. tabacum is selected for the study.

Dandruff is the shedding of dead skin cells from the scalp. The causative agents of dandruff belong to the group of scalp commensal lipophilic yeasts of the genus, Malassezia furfur Dandruff" (also referred as "Pityriasis simplex") is characterized by scaling of the scalp, which may be associated with seborrhoea and is considered as the precursor of seborrheic dermatitis (De Angelis et al 2007). The yeast, Pityrosporum ovale is implicated as the contributing organism in the etiology of dandruff, due to its lipase activity (which releases proinflammatory free fatty-acids) and its ability to activate the alternative complement pathway.

The process in which suitable modification of substrate structure is achieved by biological enzyme catalysis is termed as biotransformation. There are the following three ways with the help of which the biotransformation process is carried out ${ }^{18}$.

1. With purified culture of microorganisms.

Ex. Bacteria or Fungi or Yeast.

2. With plant cell culture or tissue culture

3. With isolated purified microbial or plant or animal cell enzyme.

General goals of biotransformation can be listed as follows:

Specific modification of substrate molecule via selective transformation reaction

Partial degradation of substrate molecule into desirable metabolites by means of controlled microbial reaction or reaction pathway

Extension of substrate or by the use of biosynthetic reactions to form artificial products

Biotransformation gained it's present status only after discovery of microbial transformations of steroids viz. Reduction of androstensdione to testosterone through yeast, 11-hydroxylation of progesterone by Rhizopus arrhizus.

Very few biotransformation studies have been carried out regarding the chemical study of biotransformed products and their pharmacological evaluation. Biotransformation with alcohol, with water have been done however the biotransformation with cow urine has not been done yet. It was therefore envisaged to evaluate the biotransformation potential of Cow urine as an extraction medium and subsequent impact on the efficacy of its extract ${ }^{8}$.

Microbial biotransformation employs microorganisms for achieving the desired conversion of various substrates. Microorganisms can catalyze the reactions which otherwise are difficult to carry out. The success of microbial biotransformation depends greatly on proper selection of microorganisms. The well-known enrichment techniques are used for isolation of potent microbial agents. These often employ enrichment cultures obtained from soils, decomposing materials, sewage plants, river water or factory grounds etc. The sample is incubated in a growth medium containing substrate to be transformed as sole carbon source. Microorganisms employ both constitutive as well as inducible enzymes to degrade and synthesize a great variety of compounds. 
The discovery of the phenomenon of microbial biotransformation of complicated organic compounds provided impetus to employ microorganisms in the production of novel agents ${ }^{15}$. Gradually, the methods of preparing new derivatives of known substrates were applied to modify organic compounds like Carbohydrates, steroids, sterols, terpenoids, flavonoids, alkaloids, antibiotics, amino acids etc. Such alteration encompasses many changes in the substrate moiety by the addition, degradation or modification. When basic structure of resultant molecule remains unaltered, the microbial biotransformation can be applied for formation of desired derivatives of precursor.

Traditionally, cow urine itself has some medicinal properties and employing it in the process of extraction through biotransformation is envisaged to have positive improvement in the original potency of the herb under study.

\section{Materials and Methods}

\subsection{Plant Material}

\subsubsection{Procurement of Nicotiana tabacum Leaves}

Controlled, partly dried leaves of Nicotiana tabacum were procured from local market .

Cow urine was procured from Govigyan Anusandhan Kendra, Dewlapar, Nagpur

\subsubsection{Authentication}

The leaves were authenticated by Dr. Dongarwar, Department of Botany, R.T.M. Nagpur University, Nagpur, with the herbarium voucher specimen number 9761.

\subsection{Preparation of Extract}

The collected leaves about $200 \mathrm{gm}$. were macerated in cow urine (1 Lit.) for time period of 28 days $^{12}$. After the completion of this time period, the biotransformed material (Extract) was harvested, lyophilized, powdered (20 gm.) which was then used for further studies.

\subsubsection{Preparation of Aqueous Extract for Comparative Study}

The collected leaves about 200gm. were macerated in water ( 1 Lit.) for time period of 28 days. After the completion of this time period, the biotransformed aqueous extract was harvested, lyophilized, powdered (20 gm.) which was then used for further studies.

\subsection{Determination of Anti dandruff Activity of Biotransformed N.tabacum Leaves Extract, Distilled Cow Urine and Aqueous Biotransformed Extracts}

\subsubsection{Microorganism Used}

The test organism used in this study was Malassezia furfur (MTCC 1374). The culture was obtained from Microbial Type Culture Collection, Chandigarh, India.

\subsubsection{Media Preparation}

The media and other microbiology accessories were obtained from Hi-media. Sabaroud dextrose broth and sabaroud dextrose agar were used for the culture of Malassezia furfur.

\subsubsection{Dilution of Extracts}

Dilution of extracts (Cow-urine) was made by using distilled water. Dilutions are made in $\mu \mathrm{g} / \mathrm{ml}$

\subsubsection{Fungal Inoculum Preparation}

The Malassezia furfurculture was maintained in sabaroud dextrose agar plates, slants and was further subcultured before use. The mother inoculum was maintained at $30^{0} \mathrm{C}$ for about 7 days.

\subsection{Determination of Anti Dandruff Activity of Distilled Cow Urine and Biotransformed Material ${ }^{2}$}

The biotransformed material N.tabacum were tested against the dandruff causing fungus Malassezia furfur using agar diffusion method. About 20-25 ml of potato dextrose agar medium for each Petriplate cooled to $45{ }^{\circ} \mathrm{C}$ and was added to presterilized plates $(150 \mathrm{~mm}$ in size). After this, $0.1 \mathrm{ml}$ of $12-16 \mathrm{hrs}$. Old cultures of fungal strain was spreaded over the agar plates. Petri plates were allowed to dry. About four wells in each plate of $6 \mathrm{~mm}$ diameter was punched in agar surface with the help of sterilized cork borer for sphere for 
Table 1: Showing the MIC of distilled cow urine

\begin{tabular}{lcc}
\hline Sr. No. & $\begin{array}{c}\text { Concentration of } \\
\text { distilled cow urine }\end{array}$ & $\begin{array}{c}\text { Zone of inhibition } \\
\text { M.furfur }\end{array}$ \\
\hline 1. & $3 \mathrm{ml}$ & No zone \\
2. & $2.5 \mathrm{ml}$ & No zone \\
3. & $2.0 \mathrm{ml}$ & No zone \\
4. & $1.5 \mathrm{ml}$ & No zone \\
\hline
\end{tabular}

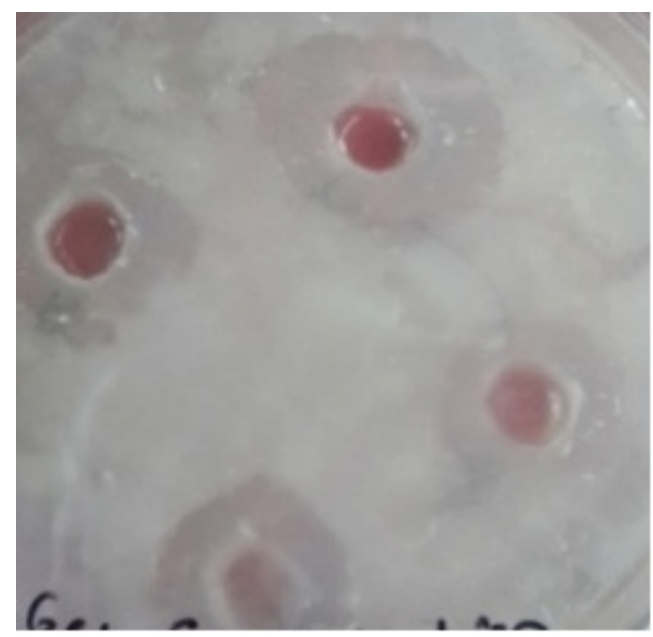

Fig. 1. Anti-dandruff activity of Distilled cow urine M. furfur.

Table 2: Showing the MIC of biotransformed material of N.tabacum

\begin{tabular}{lcc}
\hline Sr. No. & $\begin{array}{c}\text { Concentration of } \\
\text { biotransformed material } \\
\text { of N.tabacum (in } \mathrm{mg} / \mathrm{ml} \text { ) }\end{array}$ & $\begin{array}{c}\text { Zone of inhibition } \\
\text { (in } \mathrm{mm} \text { ) (M. furfur) }\end{array}$ \\
\hline 1. & 500 & 16 \\
2. & 100 & 7 \\
3. & 50 & No zone \\
4. & 25 & No zone \\
5. & 12.5 & No zone \\
\hline
\end{tabular}

placing the extracts, about $20 \mu \mathrm{l}$ of biotransformed material was added into well. The plates were kept for incubation at $30^{\circ} \mathrm{C}$ for about 48 to 72 hours. After 72 hours of incubation the zone of inhibition was clearly visible and the diameter of the zone was measured and tabulated.

\subsection{Antidandruff Activity of N.tabacum Biotransformed Material against M.furfur}

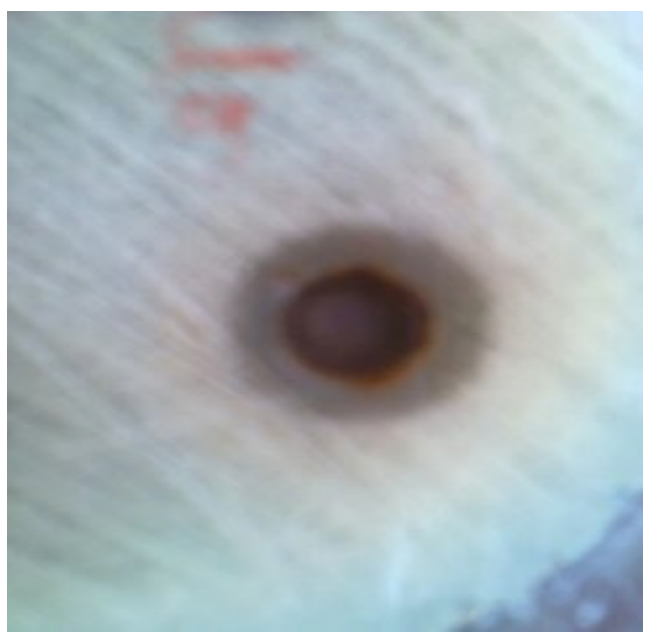

Fig. 2. $100 \mathrm{ppm}$ material.

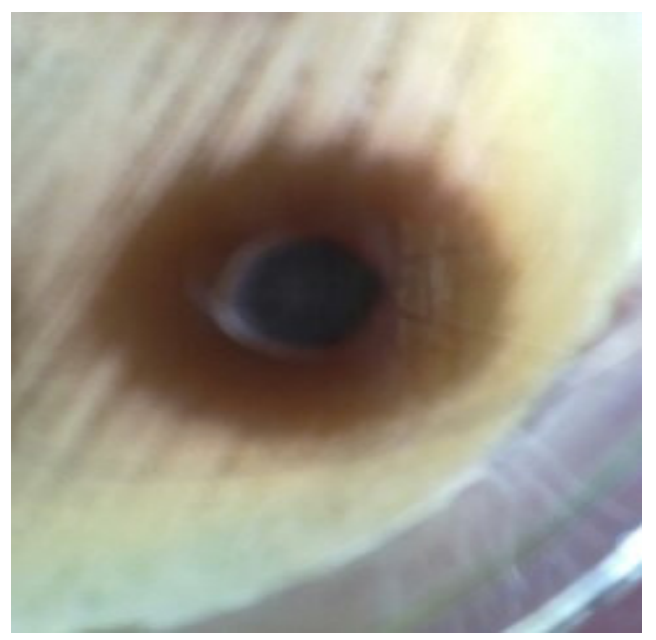

Fig. 3. $500 \mathrm{ppm}$ material.

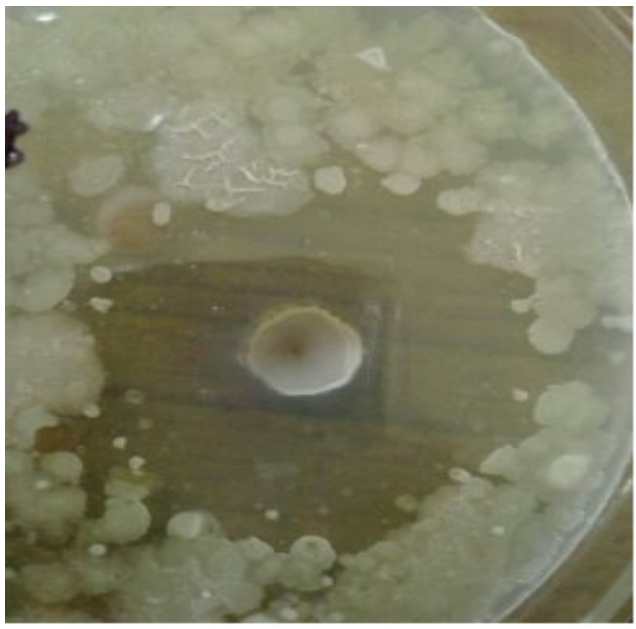

Fig. 4. Antidandruff activity of Ketoconazole against M.furfur. 
Table 3: Showing the MIC of Ketoconazole

\begin{tabular}{lcc}
\hline $\begin{array}{c}\text { Sr. } \\
\text { No. }\end{array}$ & $\begin{array}{c}\text { Concentration of } \\
\text { Ketoconazole shampoo } \\
\mathrm{mg} / \mathrm{mL}\end{array}$ & $\begin{array}{c}\text { Zone of Inhibition in } \\
\mathrm{mm}\end{array}$ \\
\hline 1 & 20 & 28
\end{tabular}

Table 4: Showing the Anti dandruff activity of aqueous extract of N.tabacum leaves

\begin{tabular}{lcc}
\hline Sr. No. & $\begin{array}{c}\text { Concentration of } \\
\text { aqueous extract } \\
\text { (in } \mathrm{mg} / \mathrm{ml} \text { ) }\end{array}$ & $\begin{array}{c}\text { Zone of inhibition } \\
\text { M.furfur }\end{array}$ \\
\hline 1. & 500 & No zone \\
2. & 100 & No zone \\
3. & 50 & No zone \\
\hline
\end{tabular}

\subsection{Antidandruff Activity of Aqueous Extract N.tabacum Leaves against M.furfur}
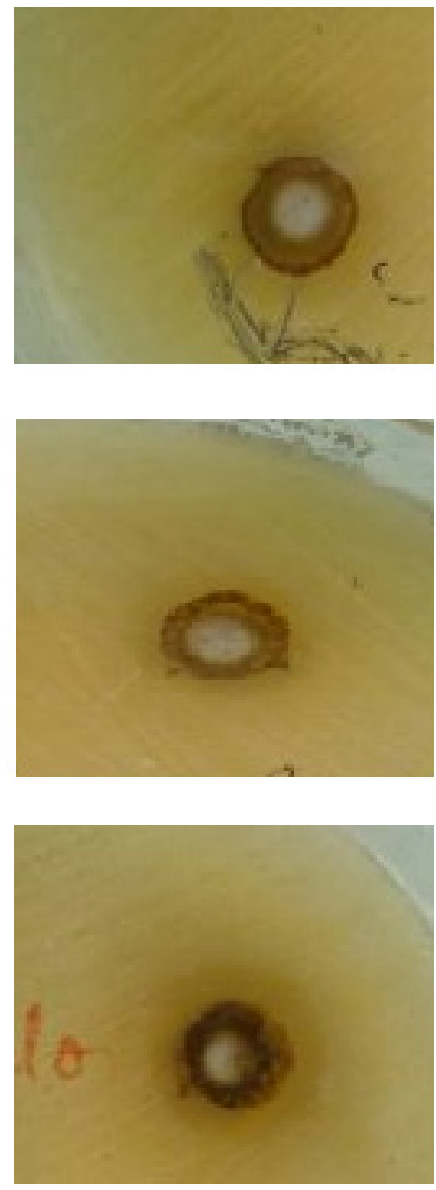

Fig. 5. Antidandruff activity of aqueous extract N.tabacum leaves against M.furfur.

\section{Results and Discussion}

Microbial biotransformation and the further studies on its therapeutical potential is envisaged in this research work. Evaluation of antidandruff activity was executed following Agar diffusion Cup Plate method against Malassezia furfur which is well known strain of fungus responsible for dandruff in human being ${ }^{2}$. The biotransformed extracts of the plants under study shown significant potential to arrest the growth of $M$. furfur against the marketed samples. Results clearly shows that the distilled cow urine did not show the anti-dandruff activity and also the aqueous extract of N.tabacum at different concentrations failed to elicit it's anti dandruff capabilities. However, the biotransformed extract of the same at the concentration of 50,100 and $500 \mathrm{mg} / \mathrm{ml}$ have shown the concentration dependent anti-dandruff activity.

\section{Conclusion}

Cow urine itself has a unique place in Ayurveda, the ancient Indian system of medicine, as cow urine is useful in various manners, particularly in the management of human health. There is no doubt about various products which are obtained using cow urine, as the efficacy of the products may be the same or more than that of only cow urine. By considering this fact it is possible to develop some novel medicines and novel molecules by treating the herbal drug with cow urine to get some best formulations. One of the better way to use the cow urine would be through its biotransformation capabilities, in which herbal drug is allowed to be kept in contact with cow urine for substantially long period of time and resultant is then considered useful as biotransformed product for curing the diseases more effectively. Hence, in this research as per the literature and importance of cow urine in ancient system of medicine like Ayurveda for various diseases, selection of cow urine as a medium for biotransformation was envisaged.

The anti-dandruff studies of Nicotiana tabacum obtained after biotransformation using cow urine as an extraction medium on $M$. furfur shows inhibition of $M$. furfur. The results showed that the maximum inhibition of fungal strain by Nicotiana tabacum biotransformed material and was found to be more than 50\% with compare to synthetic drug ketoconazole at a dose of up to 
$500 \mathrm{mg} / \mathrm{ml}$. Hence biotransformed material of Nicotiana tabacum obtained by using cow urine as medium for extraction can be used as a potent anti-dandruff agent.

\section{Acknowledgement}

We wish to thank the Govigyan Anusandhan Kendra, Dewlapar, Nagpur, for providing distilled cow urine and Microbial Type Culture Collection, Chandigarh, India for providing fungal strain.

\section{References}

1. Ates DA, Erdogrul OT. Antimicrobial activities of various medicinal and commercial plant extracts. Turk J Biol. 2003; 27:157-62.

2. Selvakumar P, Edhaya NB, Prakash D. Studies on the antidandruff activity of the essential oil of coleus amboinicus and eucalyptus globules. Asian Pacific Journal of Tropical Biomedicine. 1985; 213-6.

3. Balakrishnan KP, Narayanswamy N, Mathews S, Gurung K. Evaluation of some medicinal plants for their dandruff control properties. International Journal of Pharma and Bio sciences. 2010; 2:38-45.

4. Chopra RN, Chopra IC, Handa KL, Kapur LD. Indigenous Drugs of India; Academic Publications. 1982; 510-1.

5. DeAngelis YM, Saunders CW, Johnstone KR. Isolation and expression of a Malassezia furfur lipase gene, LIP1. J Invest. Dermatol. 2007; 127(9):2138-46.

6. Nadkarni. Indian Materia Medica. Vol. 2. Popular Prakashan. 1976; 3:850-7.

7. Inamadar AC, Palit A. The genus Malassezia and human disease. Indian J Dermatol Venereol Leprol. 2003; 69(4):265-70.

8. Wang J, Ze L, Jessie L-S. Au Pharmaceutical Research. 2006; 11:45-6.

9. Kasiram K, Sakharkar PR, Patil AT. Antifungal activity of Calendula officinalis. 1987; 543-8.
10. Kaushik RD, Gupta, Yadav R, et al. Alopecia and Herbal Remedies. International Journal of Pharmaceutical Science and Research. 2011; 2(7):1631-7.

11. Kirtikar KR, Basu BD. Indian Medicinal Plants. International Book Distribution. 1975; 3:1798-9.

12. Murkute AV, Sahu MS, Mali PY, Rangari VD. Development and Evaluation of Formulations of Microbial Biotransformed Extract of Tobacco Leaves for Hair Growth Potential. Pharmacognosy Research. 2010; 2(5):300-3.

13. Misal G, Dixit G, Kulkarni V. Indian journal of Natural Product and Resources. 2012; 4:501-5.

14. Maria CS, Souza M, Pinheiro A, Ferreira M, Goncalves R, Cristin T, Peralta M. Evaluation of antitubercular activity of nicotinic and isoniazid analogues. Arkivoc. 2007; 14:181-91.

15. Sato N, Leopold PL, Ronald G. Crystal. Journal of the National Cancer Institute. 2001; 24:1859-64.

16. Pandit NK, Wang D. Salts effects on the diffusion and release rate of propranolol from poloxamer 407 gels. International Journal of Pharmacy. 1998; 167:183-9.

17. Chopra RN, Nayar SL, Chopra IC. Glossary of medicinal plants. New Delhi: CSIR; 1976. p. 375-80.

18. Rehm HJ, Verghase G. Biotransformations, Biotechnology. Vol. 6a. 1984. p. 1-25, 209-34, 245-64, 304-9.

19. Schmolka I. Artificial skin, preparation and properties of Pluronic F-127 gels for the treatment of the burns. J Biomed Mater Res. 1972; 6:571-82.

20. Sagar R, Dixit VK. Formulation and evaluation of herbal anti-dandruff shampoo. Nigerian Journal of Natural Products and Medicine. 2005; 9:55-60.

21. Wang H, Zhao M, Yang B, Jiang Y, Rao G. Identification of polyphenols in tobacco leaf and their antioxidant and antimicrobial activities. Food Chemist. 2008; 107:1399-406.

22. Yildirim A, Mavi A, Kara AA. Determination of antioxidant and antimicrobial activities of Rumex crispus L.extract. J Agric and Food Chemist. 2001; 49:4083-9.

23. The Wealth of India. vol. 2. New Delhi: CSIR; 1998. p. $177-81$. 